\title{
Predicting the outcome from NIV for acute exacerbations of COPD
}

\author{
J V J Lightowler, M W Elliott
}

The use of non-invasive ventilation (NIV) in the management of acute exacerbations of chronic obstructive pulmonary disease (COPD) is now supported by a number of randomised controlled trials. ${ }^{1-5}$ It has been shown to reduce intubation rates, ${ }^{13-5}$ mortality, ${ }^{12-5}$ and length of stay. ${ }^{14}$ It has the advantage that it can be applied intermittently, avoids the need for sedation, and allows the patient to eat, drink and talk. The incidence of nosocomial pneumonia during NIV is lower than in intubated patients..$^{6-8}$ NIV has the additional advantage that it can be used with success outside the intensive care unit (ICU), thereby reducing the demand on ICU beds. ${ }^{5}$

However, NIV is not without its problems. The mask can be uncomfortable and claustrophobic for an acutely dyspnoeic patient, it can cause facial skin necrosis and, if poorly fitted, may be associated with large amounts of leakage which may compromise the efficiency of ventilation. Gastric distension is also recognised. Without the presence of an endotracheal/tracheostomy tube the lower airway cannot be easily accessed which makes bronchial toilet difficult. NIV is not successful in all cases of acute on chronic respiratory failure due to COPD, with reported failure rates of $7-50 \%{ }^{4}{ }^{9}$ There has also been concern that NIV may delay intubation leading to a worse outcome. ${ }^{10} 11$

The ability to predict those likely to fail with NIV is important. Patients in whom there is a high likelihood of failure would be spared the discomfort of a trial of NIV and intubation would not be delayed. It would also be helpful in determining where NIV should take place; a patient with a high likelihood of failing, and for whom intubation would be considered appropriate, is best managed in the ICU, whereas the patient who is likely to be successfully treated with NIV can be managed on the ward.

A number of studies have looked at predictors of outcome for NIV in acute exacerbations of COPD. ${ }^{1}{ }^{2}$ 12-17 The major limiting factor is that prediction models are only as good as the data entered; data that are not collected cannot be entered into the model. Furthermore, the chosen outcome may influence the results. For instance, if the failure of blood gas tensions to improve within a certain time is taken as an indication for intubation, then by default this will become a failure criterion even though success might have been achieved with persistence and adjustment of ventilator settings.

Acidosis is an indicator of the severity of decompensation in acute on chronic ventilatory failure and has been shown to predict death in a number of studies of acute exacerbations of COPD. ${ }^{218-20}$ It is therefore a logical starting point for identifying patients who might benefit from NIV. In a retrospective review aimed at identifying patients with COPD who could be treated successfully with NIV, Ambrosino et $a l^{12}$ found that patients in whom NIV treatment failed were significantly more acidaemic at baseline than those successfully treated ( $\mathrm{pH} 7.22$ (SD 0.08) versus 7.28 (0.04), $\mathrm{p}<0.005)$. Although using a discriminant analysis a number of variables such as neurological status score, APACHE II, baseline $\mathrm{pH}, \mathrm{PaCO}_{2}$, and $\mathrm{pH}$ during NIV had a predictive value of $>0.80$ for successful NIV, when tested together using logistic regression analysis only baseline $\mathrm{pH}$ maintained a significant predictive effect with a sensitivity of $97 \%$ and specificity of $71 \%$. Similarly, Brochard et $a l,{ }^{1}$ using a priori criteria for the need for intubation, found that success was less likely with a lower starting $\mathrm{pH}$. In contrast, a number of studies have failed to show any relationship between baseline arterial blood gas tensions and the response to NIV. ${ }^{913-17}$

Ambrosino $e t a l^{12}$ found a significantly lower forced vital capacity (FVC) in patients failing with NIV; however, pulmonary function test results were only available in just over two thirds of patients. They also found that underweight patients did less well. However, surprisingly, Antón et al ${ }^{17}$ found that a successful outcome with NIV was more likely with a lower forced expiratory volume in one second $\left(\mathrm{FEV}_{1}\right)(27(11) \%$ predicted versus $38(11) \%, \mathrm{p}<0.01)$. The cause of the acute exacerbation is also not a reliable predictor of outcome from NIV. ${ }^{912}{ }^{14} 16{ }^{17}$ In two studies $^{9}{ }^{12}$ radiological consolidation was more common in the group failing NIV, but in a prospective randomised controlled trial evaluating NIV against conventional treatment in patients with pneumonia Confalonieri et $a l^{1}$ found that, in the subgroup of patients who also had COPD, the two month survival was better in the NIV group. Age is also not a contraindication to NIV, which has been used with success in the elderly. ${ }^{16}$

The severity of the illness at presentation, as judged by the APACHE II scores, has been shown in two studies to be greater in patients who failed NIV than in those who were successfully treated (21 (4) versus $15(4), \mathrm{p}=0.02^{9}$ and 29 (4) versus $\left.18(4), p<0.0001^{12}\right)$. However these results are not supported by other studies. ${ }^{14}{ }^{15}{ }^{17}$ Using the Simplified Acute Physiology Score (SAPS), Benhamou et $a l^{16}$ also found no difference between successful and unsuccessful NIV in their study of elderly patients with acute respiratory failure and a number of different underlying lung pathologies. It has been suggested that an altered level of consciousness is a contraindication to $\mathrm{NIV},{ }^{11}$ although this is largely for theoretical reasons and because such patients have usually been excluded from clinical trials. A better level of consciousness at baseline ${ }^{1217}$ and after one hour of $\mathrm{NIV}^{17}$ has been shown to correlate with success. Brochard et $a l^{1}$ also noted that the encephalopathy score dropped significantly in patients successfully treated with NIV during the course of their treatment. However, three other studies have shown no such relationship..$^{15} 22$

Once NIV has been started, progress with treatment may indicate the likely outcome. Not surprisingly, the ability of the patients to tolerate NIV is a factor. Benhamou et $a l^{16}$ found that "tolerance" of NIV was the only factor of prognostic value. Ambrosino et $a l^{12}$ also found that better compliance was associated with a greater likelihood of success with NIV and in their prospective case series of 12 patients with hypercapnic acute respiratory failure Soo Hoo et al $l^{9}$ noted that successfully treated patients were able to tolerate NIV for longer than those who could not be successfully treated. Larger volumes of air leakage were noted in patients who failed with NIV, ${ }^{9}$ and these patients also tended to be edentulous and to breathe through pursed lips.

A number of studies have shown that the change in arterial blood gas tensions, particularly $\mathrm{pH}$, after a short period 
of NIV predicts a successful outcome. ${ }^{12} 9^{12-14}$ An improvement in $\mathrm{pH}$ and/or $\mathrm{PaCO}_{2}$ at 30 minutes, ${ }^{15}$ one hour, ${ }^{13}$ or after a longer period ${ }^{13}$ predicts successful NIV. Patients who have been intubated and are likely to fail a weaning attempt adopt a pattern of rapid shallow breathing when disconnected from the ventilator, ${ }^{23}$ indicating that they are breathing against an unsustainable load. A reduction in respiratory rate with NIV has been variably shown in a number of studies, with larger falls generally being associated with a successful outcome, ${ }^{19}{ }^{13}$ although this is not always seen. ${ }^{17}$ In the absence of a priori criteria for endotracheal intubation, it is not surprising that a failure of commonly measured physiological variables to improve prompts an escalation of therapy which in this case is a switch to invasive ventilation.

So far studies have concentrated on the ability to predict failure shortly after initiation of NIV. However, patients who fail NIV do not exclusively fail at this time. Late failure (after 48 hours of successful NIV) is recognised, with rates reported at $0-20 \%$, and has been associated with poor outcomes. In this issue of Thorax Moretti et $a l^{24}$ address the issue of late failure. In their study 137 patients admitted with COPD and acute hypercapnic respiratory failure were initially successfully treated with NIV. Of these, 106 continued to improve and were discharged home. The remaining $23 \%$ deteriorated after 48 hours. These so called "late failures" were then assigned to either an increased number of hours of NIV (the mean number of hours/day of NIV at the time of late failure was 9.2) or intubation and mechanical ventilation depending on the wishes of the patients and their relatives. Importantly, it should be noted that patients assigned to increased NIV did significantly worse with a mortality of $92 \%$ compared with $53 \%$ in those invasively ventilated. At the time of relapse those patients treated with increased NIV were more acidotic than those who were intubated $(\mathrm{pH} 7.1$ versus 7.29 ), although this difference was not statistically significant, it may simply reflect the small number of patients and suggests that the patients who were treated with increased NIV were more ill than those who were intubated. There is also the possibility that patients who were not intubated were self-selected as a group with more advanced disease since they were not offered or declined endotracheal intubation. The three month survival after hospital discharge between the initial successes and late failures was similar, indicating that the acute event does not signify a worse long term outcome. However, there are no data on the quality of life, disability scores, or readmission rate following discharge.

At the time of admission "late failures" had significantly lower activities of daily living (ADL) scores and blood pressure, were more tachycardic, and were more likely to have associated complications, particularly hyperglycaemia. $\mathrm{pH}$ was not different between the groups at admission, one hour, or 24 hours. Using logistic regression analysis a low $\mathrm{pH}$, low ADL score, and the presence of associated complications at admission were more likely in patients who failed after $\geqslant 48$ hours of NIV. Interestingly, neither the APACHE II score nor age were predictive of failure.

\section{Conclusion}

Data available at the time NIV is initiated and after a short period can predict the likelihood of success or failure with a reasonable degree of precision. The severity of acidosis at baseline emerges as an important predictor; although NIV is less likely to be effective when patients are more acidotic, ${ }^{12}$ this should not preclude a trial of NIV as the mode of ventilatory support of first choice because the benefits of NIV compared with intubation and mechanical ventilation are greater. ${ }^{1}$ The tolerance of NIV and the change in arterial blood gas tensions, particularly $\mathrm{pH}$, and respiratory rate in the early hours are reasonable predictors of the subsequent outcome. ${ }^{1212}{ }^{24} \mathrm{NIV}$ is less likely to be successful if there are associated complications or if the patient's premorbid condition is poor. ${ }^{24}$ The study by Moretti et $a l^{24}$ shows that late failure is a bad prognostic factor, with over half the patients dying even with invasive ventilation. This is more likely in patients with severe acidosis, poor functional status, and complications. However, most studies to date have been retrospective and further prospective studies are needed. These should include all variables which have been shown to be of prognostic importance in acute exacerbations of COPD and with end points which include survival following discharge from hospital and health status.

\section{J V J LIGHTOWLER}

$\mathrm{M}$ W ELLIOTT

St fames's University Hospital,

Beckett Street,

Leeds LS9 7TF, UK

email:mark.elliott@gw.sjsuh.northy.nhs.uk

1 Brochard L, Mancebo J, Wysocki M, et al. Noninvasive ventilation for acute exacerbations of chronic obstructive pulmonay disease. $N$ Engl $f \mathrm{Med}$ 1995;333:817-22.

2 Bott J, Carroll MP, Conway JH, et al. Randomised controlled trial of nasal ventilation in acute ventilatory failure due to chronic obstructive airways disease. Lancet 1993;341:1555-7.

3 Kramer N, Meyer TJ, Meharg J, et al. Randomized, prospective trial of noninvasive positive pressure ventilation in acute respiratory failure. $\mathrm{Am} \mathcal{F}$ Respir Crit Care Med 1995;151:1799-806.

4 Celikel T, Sungur M, Ceyhan B, et al. Comparison of noninvasive positive pressure ventilation with standard medical therapy in hypercapnic acute respiratory failure. Chest 1998;114:1636-42.

5 Plant PK, Owen JL, Elliott MW. A multicentre randomised controlled trial of the early use of non-invasive ventilation for acute exacerbations of chronic obstructive pulmonary disease on general respiratory wards. Lancet 2000;355:1931-5.

6 Nourdine K, Combes P, Carton M-J, et al. Does noninvasive ventilation reduce the ICU nosocomial infection risk? A prospective clinical survey. Intensive Care Med 1999;25:567-73.

7 Guerin C, Girard R, Chemorin C, et al. Facial mask noninvasive mechanical ventilation reduces the incidence of nosocomial pneumonia. A prospective epidemiological survey from a single ICU. Intensive Care Med 1997;23: 1024-32.

8 Kramer B. Ventilator-associated pneumonia in critically ill patients. Ann Intern Med 1999;130:1027-8.

9 Soo Hoo GW, Santiago S, Williams AJ. Nasal mechanical ventilation for hypercapnic respiratory failure in chronic obstructive pulmonary disease:
determinants of success and failure. Crit Care Med 1994;22:1253-61.

10 Wood KA, Lewis L, Von Harz B, et al. The use of noninvasive positive pressure ventilation in the emergency department. Chest 1998;113:1339-46.

11 Ambrosino N. Noninvasive mechanical ventilation in acute respiratory failure. Eur Respir f 1996;9:795-807.

12 Ambrosino N, Foglio K, Rubini F, et al. Non-invasive mechanical ventilation in acute respiratory failure due to chronic obstructive airways disease: correlates for success. Thorax 1995;50:755-7.

13 Meduri GU, Abou-Shala N, Fox RC, et al. Noninvasive face mask mechanical ventilation in patients with acute hypercapneic respiratory failure. Chest 1991;100:445-54.

14 Meduri GU, Turner RE, Abou-Shala N, et al. Noninvasive postive pressure ventilation via face mask: first line intervention in patients with acute hypercapnic and hypoxemic respiratory failure. Chest 1996;109:179-93.

15 Poponick JM, Renston JP, Bennett RP, et al. Use of a ventilatory support system (BiPAP) for acute respiratory failure in the emergency department. Chest 1999;116:166-71.

16 Benhamou D, Girault C, Faure C, et al. Nasal mask ventilation in acute respiratory failure. Chest 1992;102:912-7.

17 Anton A, Guell R, Gomez J, et al. Predicting the result of noninvasive ventilation in severe acute exacerbations of patients with chronic airflow limitation. Chest 2000;117:828-33.

18 Soo Hoo GW, Hakimian N, Santiago SM. Hypercapnic respiratory failure in COPD patients. Chest 2000;117:169-77.

19 Jeffrey AA, Warren PM, Flenley DC. Acute hypercapnic respiratory failure in patients with chronic obstructive lung disease: risk factors and use of guidelines for management. Thorax 1992;47:34-40.

20 Warren PM, Flenley DC, Millar JS, et al. Respiratory failure revisited: acute exacerbation of chronic bronchitis between 1961-68 and 1970-76. Lancet 1980;i:467-70.

21 Confalonieri M, Potena A, Carbone G, et al. Acute respiratory failure in patients with severe community-acquired pneumonia. A prospective randomized evaluation of noninvasive ventilation. Am $\mathcal{F}$ Respir Crit Care Med 1999;160:1585-91.

22 Wysocki M, Tric L, Wolff MA, et al. Noninvasive pressure support ventilation in patients with acute respiratory failure. Chest 1993;103:907-13.

23 Yang KL, Tobin MJ. A prospective study of indexes predicting the outcome of trials of weaning from mechanical ventilation. $N$ Engl $f \mathrm{Med}$ 1991;324:1445-50.

24 Moretti M, Cilione C, Tampieri A, et al. Incidence and causes of non-invasive mechanical ventilation failure after initial success. Thorax 2000;55:819-25. 